\title{
Profil dermatitis seboroik di Poliklinik Kulit dan Kelamin RSUP Prof. Dr. R. D. Kandou Manado periode Januari - Desember 2015
}

\author{
${ }^{1}$ Senderina Malak \\ ${ }^{2}$ Renate T. Kandou \\ ${ }^{2}$ Thigita A. Pandaleke
}

\author{
${ }^{1}$ Kandidat skripsi Fakultas Kedokteran Universitas Sam Ratulangi Manado \\ ${ }^{2}$ Bagian/SMF Kulit dan Kelamin RSUP Prof. Dr. R. D. Kandou Manado \\ Email: sendymalak@gmail.com
}

\begin{abstract}
Seborrheic dermatitis is an inflammatory superficial skin disorder with chronic papuloskuamosa in areas rich in sebaceous glands. Seborrheic dermatitis occurs in $2-5 \%$ of population. The cause of seborrheic dermatitis is still unknown, however, this disorder has a relationship with the secretion of sebaceous glands, Malassezia fungi, and the immune response. In seborrheic dermatitis, erythema with oily and slightly yellowish scaling and without distinct borders. This was a retrospective and descriptive study based on the number of cases, age group, sex, occupation, location of lesion, and type of treatment. The results showed that of 91 cases of seborrheic dermatitis (2.2\%), this disorder often occured in the age group $45-64$ years (40.7\%), male gender (67.0\%), retired (28.5\%), facial lesions (39.5\%), and treated with corticosteroid combination therapy, antihistamines, and anti-fungal (59.3\%).
\end{abstract}

Keywords: seborrheic dermatitis

\begin{abstract}
Abstrak: Dermatitis seboroik adalah kelainan kulit yang berupa peradangan superfisial dengan papuloskuamosa yang kronik pada daerah yang kaya akan kelenjar sebasea, dermatitis seboroik menyerang 2-5\% populasi. Penyebab dermatitis seboroik belum diketahui pasti, namun dermatitis seboroik memiliki hubungan dengan sekresi kelenjar sebasea, jamur Malassezia dan respon imun. Kelainan kulit dermatitis seboroik berupa eritema, skuama yang berminyak dan agak kekuningan, batasnya tidak tegas. Penelitian ini merupakan penelitian deskriptif retrospektif berdasarkan jumlah kasus, kelompok umur, jenis kelamin, pekerjaan, lokasi dan jenis pengobatan. Hasil penelitian ini menunjukkan bahwa dari 91 kasus dermatitis seboroik (2,2\%), penyakit ini sering terjadi pada kelompok umur 45-64 tahun (40,7\%), jenis kelamin laki-laki $(67,0 \%)$, pensiunan $(28,5 \%)$, lokasi lesi wajah $(39,5 \%)$ dan pengobatan kombinasi kostikosteroid, antihistamin dan antijamur (59,3\%).
\end{abstract}

Kata kunci: dermatitis seboroik

Dermatitis seboroik adalah kelainan kulit yang berupa peradangan superfisial dengan papuloskuamosa yang kronik dengan tempat predileksi di daerah-daerah seboroik yaitu daerah yang kaya akan kelenjar sebasea, seperti kepala (kulit kepala, telinga bagian luar, saluran telinga, kulit di belakang telinga), wajah (alis mata, kelopak mata, glabella, lipatan nasolabial, dagu), badan bagian atas (daerah presternum, daerah interskapula, areolla mammae), dan daerah lipatan (ketiak, lipatan mammae, umbilikus, lipatan paha, daerah anogenital dan lipatan pantat). ${ }^{1}$

Dermatitis seboroik menyerang 2-5\% populasi, dapat menyerang bayi pada tiga bulan pertama kehidupan dan dewasa umur 20 hingga 50 tahun. Di Amerika Serikat prevalensi dermatitis seboroik sekitar 1-3\% dari jumlah populasi umum, dan 3-5\% 
terjadi pada dewasa muda, ${ }^{3}$ sedangkan data di Unit Kulit Kelamin RSUP H. Adam Malik Medan periode Januari 2010 Desember 2012 sebanyak 123 kasus $(0,75 \%)$ dari 16.482 pasien yang datang berobat. $^{4}$ Penelitian di RSUP Prof. Dr. R. D. Kandou pada periode Januari Desember 2012 membuktikan bahwa dari 4.023 pasien baru yang datang berobat ke Poliklinik Kulit dan Kelamin, didapatkan 134 kasus (3,3\%) dengan dermatitis seboroik. $^{5}$

Kelainan kulit terdiri atas eritema dan skuama yang berminyak dan agak kekuningan, batasnya tidak tegas. Kelainan kulit dapat disertai rasa gatal walupun jarang. Dermatitis seboroik yang ringan hanya mengenai kulit kepala berupa skuama-skuama yang halus, awalnya bercak kecil yang kemudian mengenai seluruh kulit kepala dengan skuamaskuama yang halus dan kasar. ${ }^{6-8}$

Berdasarkan riwayat penyakit, pemeriksaan fisik dan pemeriksaan penunjang diagnosis dermatitis seboroik dapat ditegakkan. Beberapa diagnosis banding dermatitis seboroik, yaitu psoriasis, dermatitis atopik, dermatitis kontak dan juga eritrasma. ${ }^{9}$

Pendekatan terapi saat ini umumnya didasarkan pada anti jamur topikal, agen anti inflamasi dan imunomodulator. ${ }^{10}$ Untuk pengobatan sistemik dapat digunakan kortikosteroid, isotretinoin, narrow band UVB (TL-01) pada dermatitis seboroik yang parah serta ketokonazol pada sediaan $P$. ovale yang banyak. ${ }^{8}$

Data terakhir mengenai dermatitis seboroik di RSUP Prof. Dr. R. D. Kandou yaitu tahun 2012. Penelitian ini bertujuan untuk mendapatkan profil dermatitis seboroik dan peningkatan atau penurunan jumlah pasien yang datang memeriksakan diri di Poliklinik Kulit dan Kelamin RSUP Prof. Dr. R. D. Kandou Manado.

\section{METODE PENELITIAN}

Penelitian ini menggunakan metode deskriptif retrospektif dengan menggunakan catatan rekam medik pasien dermatitis seboroik yang tercatat di Poliklinik Kulit dan Kelamin serta Instalasi Rekam Medik RSUP Prof. Dr. R. D. Kandou Manado periode Januari-Desember 2013. Populasi mencakup seluruh kasus yang tercatat menderita penyakit kulit di Poliklinik Kulit dan Kelamin RSUP Prof. Dr. R. D. Kandou Manado periode JanuariDesember 2012 dan sampel penelitian yaitu seluruh kasus yang tercatat menderita dermatitis seboroik. Variabel penelitian yaitu jumlah kasus, kelompok umur, jenis kelamin, pekerjaan, lokasi dan jenis pengobatan.

\section{HASIL PENELITIAN}

Berdasarkan penelitian deskriptif retrospektif dari bulan Oktober - Desember 2015 pada penderita dengan diagnosis dermatitis seboroik di Poliklinik Kulit \& Kelamin serta Instalasi Rekam Medik RSUP Prof. Dr. R. D. Kandou Manado periode Januari-Desember 2013 didapatkan distribusi kasus dermatitis seboroik berdasarkan jumlah kasus tahun 2013 sebanyak 91 kasus (2,2\%) dari 4.099 kasus di Poliklinik Kulit dan Kelamin RSUP Prof. Dr. R. D. Kandou Manado.

Tabel 1. Distribusi Kasus Dermatitis Seboroik Berdasarkan Jumlah Kasus di RSUP Prof. Dr. R. D. Kandou Manado Tahun 2013

\begin{tabular}{cccc}
\hline Tahun & $\begin{array}{c}\text { Jumlah Seluruh } \\
\text { Kasus di } \\
\text { Poliklinik Kulit \& } \\
\text { Kelamin }\end{array}$ & $\begin{array}{c}\text { Jumlah } \\
\text { Kasus } \\
\text { Dermatitis } \\
\text { Seboroik }\end{array}$ & $\%$ \\
\hline 2013 & 4099 & 91 & 2,2 \\
\hline
\end{tabular}

Distribusi kasus dermatitis seboroik berdasarkan umur pasien saat memeriksakan diri di Poliklinik Kulit dan Kelamin RSUP Prof. Dr. R. D. Kandou periode Januari - Desember 2013, didapatkan kasus terbanyak pada golongan umur 45-64 tahun berjumlah 37 kasus $(40,7 \%)$ dan diikuti golongan umur $\geq 65$ tahun sebanyak 27 kasus (29,7\%). Golongan umur yang paling sedikit yaitu 15-24 tahun berjumlah 4 kasus $(4,4 \%)$ dan tidak terdapat kasus pada golongan umur 14 tahun selama 2013. 
Tabel 2. Distribusi Kasus Dermatitis Seboroik Berdasarkan Umur

\begin{tabular}{ccc}
\hline Umur & Jumlah Kasus & $\%$ \\
\hline$<1$ & 6 & 6,6 \\
$1-4$ & 0 & 0 \\
$5-14$ & 6 & 6,6 \\
$15-24$ & 4 & 4,4 \\
$25-44$ & 11 & 12,0 \\
$45-64$ & 37 & 40,7 \\
$\geq 65$ & 27 & 29,7 \\
Total & 91 & 100,0 \\
\hline
\end{tabular}

Distribusi kasus dermatitis seboroik berdasarkan jenis kelamin di Poliklinik Kulit dan Kelamin RSUP Prof. Dr. R. D. Kandou periode Januari - Desember 2013, didapatkan jumlah kasus pada laki-laki lebih banyak daripada perempuan. Jumlah kasus pada laki-laki sebanyak 61 kasus $(67,0 \%)$ sedangkan perempuan sebanyak 30 kasus $(33,0 \%)$.

Tabel 3. Distribusi Kasus Dermatitis Seboroik Berdasarkan Jenis Kelamin

\begin{tabular}{ccc}
\hline Jenis kelamin & $\begin{array}{c}\text { Jumlah } \\
\text { kasus }\end{array}$ & $\%$ \\
\hline Laki-laki & 61 & 67,0 \\
Perempuan & 30 & 33,0 \\
Total & 91 & 100,0 \\
\hline
\end{tabular}

Distribusi kasus dermatitis seboroik berdasarkan pekerjaan pasien di Poliklinik Kulit dan Kelamin RSUP Prof. Dr. R. D. Kandou periode Januari - Desember 2013, didapatkan kasus terbanyak yaitu pensiunan berjumlah 26 kasus (28,5\%), diikuti PNS dan yang tidak bekerja yang memiliki jumlah kasus yang sama yaitu 14 kasus (15,4\%). Golongan pekerjaan yang paling sedikit yaitu tukang ojek dan nelayan dimana jumlah kasusnya sama banyak yakni 1 kasus (1,1\%) (Tabel 4).

Distribusi kasus dermatitis seboroik berdasarkan lokasi di Poliklinik Kulit dan Kelamin RSUP Prof. Dr. R. D. Kandou periode Januari - Desember 2013, didapatkan jumlah lokasi paling banyak pada wajah yaitu 36 kasus (39,5\%), diikuti lokasi kombinasi (badan, kepala, lengan atas, wajah) sebanyak 19 kasus (20,9\%).
Lokasi paling sedikit yaitu pada daerah lengan atas sebanyak 4 kasus (4,4\%) (Tabel 5).

Tabel 4. Distribusi Kasus Dermatitis Seboroik Berdasarkan Pekerjaan

\begin{tabular}{ccc}
\hline Jenis Pekerjaan & Jumlah Kasus & $\%$ \\
\hline Pelajar & 7 & 7,7 \\
Ibu Rumah & 5 & 5,5 \\
Tangga & 1 & 1,1 \\
Tukang Ojek & 1 & 1,1 \\
Nelayan & 10 & 11,0 \\
Petani & 14 & 15,4 \\
PNS & 13 & 14,3 \\
Swasta & 26 & 28,5 \\
Pensiunan & 14 & 15,4 \\
Tidak bekerja & & \\
\hline Total & \multirow{2}{*}{100,0} \\
\hline
\end{tabular}

Tabel 5. Distribusi Kasus Dermatitis Seboroik Berdasarkan Lokasi

\begin{tabular}{lcc}
\hline \multicolumn{1}{c}{ Lokasi } & Jumlah kasus & $\%$ \\
\hline Kepala & 18 & 19.8 \\
Wajah & 36 & 39.5 \\
Badan & 14 & 15.4 \\
Lengan Atas & 4 & 4.4 \\
Kombinasi & 19 & 20.9 \\
\hline \multicolumn{1}{c}{ Total } & 91 & 100.0 \\
\hline Kombinasi: kepala, wajah
\end{tabular}

Kombinasi: kepala, wajah, badan, lengan atas

Tabel 6. Distribusi Kasus Dermatitis Seboroik Berdasarkan Jenis Pengobatan

\begin{tabular}{ccc}
\hline Jenis pengobatan & $\begin{array}{c}\text { Jumlah } \\
\text { kasus }\end{array}$ & $\%$ \\
\hline KS (Topikal + Oral) & 27 & 29,7 \\
KS+AH+AJ & 54 & 59,3 \\
KS+AH+AB & 10 & 11,0 \\
Total & 91 & 100,0 \\
\hline
\end{tabular}

KS: kortikosteroid; AH: antihistamin; AJ: antijamur; AB: antibiotik

Distribusi kasus dermatitis seboroik berdasarkan jenis pengobatan di Poliklinik Kulit dan Kelamin RSUP Prof. Dr. R. D. Kandou periode Januari-Desember 2013, didapatkan pengobatan terbanyak kombinasi kostikosteroid (KS), antihistamin (AH) dan antijamur (AJ) dengan jumlah 54 kasus (59,3\%) dan pengobatan terendah kombinasi kortikosteroid (KS), antihista- 
min (AH) dan antibiotik (AB) sebanyak 10 kasus $(11,0 \%)$.

\section{BAHASAN}

Dari hasil penelitian retrospektif yang dilakukan di Poliklinik Kulit dan Kelamin serta Instalasi Rekam Medik RSUP Prof. Dr. R. D. Kandou Manado periode JanuariDesember 2013 diperoleh 91 kasus dermatitis seboroik (2,2\%) dari 4.099 pasien yang datang ke Poliklinik Kulit dan Kelamin. Jika dibandingkan dengan prevalensi pasien dermatitis seboroik periode Januari-Desember 2012 didapatkan $3,3 \%,{ }^{5}$ maka terlihat adanya penurunan jumlah pasien dermatitis seboroik yang datang ke Poliklinik Kulit dan Kelamin RSUP Prof. DR. R. D. Kandou Manado. Hal ini mungkin disebabkan karena sesuai dengan Standar Kompetensi Dokter Indonesia bahwa dermatitis seboroik masuk dalam tingkat kemampuan 4A dimana DS dapat didiagnosis serta dilakukan penatalaksanaan secara mandiri dan tuntas oleh dokter umum sehingga terjadi penurunan jumlah pasien yang datang ke Poliklinik Kulit dan Kelamin RSUP Prof. Dr. R. D. Kandou Manado. Hasil data ini (Tabel 2) masih jauh lebih tinggi jika dibandingkan dengan prevalensi pasien dermatitis seboroik di Unit Kulit Kelamin RSUP H. Adam Malik Medan periode Januari 2010 - Desember 2012 sebanyak 123 kasus (0,75\%) dari 16.482 pasien yang datang berobat. ${ }^{4}$ Hal ini mungkin dikarenakan pengetahuan masyarakat yang masih kurang tentang dermatitis seboroik sehingga mereka belum dapat menghindari faktor pencetus seperti menjaga kebersihan tubuh dimana salah satu penyebab dermatitis seboroik yakni jamur Malassezia yang merupakan flora normal pada tubuh. Perilaku yang buruk dalam menjaga kebersihan tubuh dapat menyebabkan flora normal bertumbuh menjadi patogen.

Distribusi kasus dermatitis seboroik berdasarkan umur (Tabel 3) terbanyak pada golongan umur 45-64 tahun sebanyak 37 kasus (40,7\%) dan diikuti golongan umur $\geq 65$ tahun sebanyak 27 kasus $(29,7 \%)$, kemudian golongan umur 25-44 sebanyak
11 kasus (12,0\%). Hasil ini tidak jauh berbeda dengan penelitian sebelumnya oleh Terroe periode Januari-Desember 2012 di Poliklinik Kulit dan Kelamin RSUP Prof. Dr. R. D. Kandou diperoleh golongan umur terbanyak yang menderita dermatitis seboroik yaitu golongan umur 45-64 tahun dari 74 kasus $(55,2 \%){ }^{5}$ Insiden dermatitis seboroik mencapai puncak pada dewasa 2050 tahun. $^{2}$ Pada pasien dengan usia lanjut memiliki daya tahan tubuh yang sudah berkurang sehingga lebih rentan terhadap berbagai macam penyakit salah satunya seperti dermatitis seboroik.

Distribusi kasus dermatitis seboroik berdasarkan jenis kelamin (Tabel 4) diperoleh jumlah pasien laki-laki lebih banyak dibandingkan perempuan. Jumlah laki-laki sebanyak 61 kasus (67,0\%) dan perempuan sebanyak 30 (33,0\%). Insiden ini sama dengan penelitian sebelumnya oleh Terroe periode Januari-Desember 2012 di Poliklinik Kulit dan Kelamin RSUP Prof. Dr. R. D. Kandou, laki-laki merupakan pasien terbanyak yaitu 90 kasus $(67,2 \%)$ dan perempuan 44 kasus $(32,8 \%){ }^{5}$ Hal ini kemungkinan berhubungan dengan stimulasi hormon androgen yang lebih tinggi pada laki-laki dibandingkan perempuan. Hormon androgen memiliki fungsi untuk menghasilkan sebum, dimana aktivitas sebum merupakan salah satu penyebab dermatitis seboroik.

Distribusi kasus dermatitis seboroik berdasarkan pekerjaan (Tabel 5) didapatkan pensiunan yang paling banyak menderita dermatitis seboroik yaitu sebanyak 26 kasus (28,5\%). Hal ini disebabkan karena pada usia pensiunan yang sudah lanjut kelenjar sebasea mencapai puncak aktifnya, ${ }^{8,14}$ dan mungkin karena mereka sudah pensiun dari pekerjaannya sehingga cenderung aktivitas yang dilakukan semakin berkurang. Aktivitas yang semakin berkurang ini dapat menyebabkan beberapa faktor pencetus dermatitis seboroik seperti stres, kurang tidur dan pola makan yang terganggu.

Distribusi berdasarkan lokasi terbanyak, (Tabel 6), didapatkan daerah wajah sebanyak 36 kasus (39,5\%), diikuti 
lokasi yang kombinasi sebanyak 19 kasus (20,9\%). Terbanyak ketiga yaitu kepala sebanyak 18 kasus (19,8\%). Predileksi dermatitis seboroik bisanya pada lokasilokasi yang mengandung banyak kelenjar sebasea, seperti wajah dan kepala. ${ }^{1,2}$

Pengobatan yang sering digunakan pada kasus dermatitis seboroik di RSUP Prof. Dr. R. D. Kandou Manado, yaitu secara topikal. Distribusi berdasarkan jenis pengobatan (Tabel 7) yang paling banyak diberikan yaitu kombinasi antara kortikosteroid (topikal + oral), antihistamin dan antijamur sebanyak 54 kasus (59,3\%), diikuti pengobatan dengan kortikosteroid (topikal + oral) sebanyak 27 kasus (29,7\%), serta kombinasi antara kortikosteroid, antihistamin dan antibiotik sebanyak 10 kasus (11,0\%). Pengobatan kombinasi kortikosteroid topikal dan oral bertujuan untuk mengurangi reaksi inflamasi, antijamur bertujuan untuk menurunkan populasi jamur malassezia dan antihistamin untuk mengurangi rasa gatal serta reaksi alergi. Pengobatan kombinasi juga bertujuan untuk mencegah rekurensi. Pengobatan dengan kortikosteroid oral atau kombinasi topikal dan oral digunakan pada kasus dermatitis seboroik yang berat. Pengobatan dengan tambahan antibiotik biasanya digunakan pada dermatitis seboroik yang yang disertai infeksi sekunder. ${ }^{3,8}$

\section{SIMPULAN}

Berdasarkan hasil penelitian retrospektif di Poliklinik Kulit dan Kelamin serta Instalasi Rekam Medik RSUP Prof. Dr. R. D. Kandou Manado periode JanuariDesember 2013, dapat disimpulkan bahwa kasus dermatitis seboroik didapatkan sebanyak 91 kasus (2,2\%). Dermatitis seboroik paling banyak ditemukan pada kelompok umur 45-64 tahun, kasus pada laki-laki lebih banyak dibanding perempuan. Pensiunan lebih banyak menderita dermatitis seboroik, wajah merupakan lokasi lesi terbanyak, serta pengobatan terbanyak digunakan kombinasi kostikosteroid, antihistamin dan antijamur.

\section{DAFTAR PUSTAKA}

1. Murtiastutik D, Ervianti E, Sunarso S. Atlas Penyakit Kulit \& Kelamin (2nd ed). Surabaya: Pusat Penerbit dan Percetakan Unair, 2007.

2. Plewig G, Jansen T. Seborrheic Dermatitis. In: Goldsmith LA, Katz SI, Gilchrest BA, Paller AS, Leffell DJ, Wolff K, editors. Fitzpatrick's Dermatology in General Medicine (8th ed). New York: McGraw-Hill, 2008; p.259-66.

3. Rook A. Seborrheic Dermatitis. In: Burns T, Breathnach S, Cox N, Griffiths C, editors. Rook's Textbook of Dermatology (8th ed). Chichester: Wiley-Blackwell, 2010; p.1013-7.

4. Lubis NZ, Nasution LH, Muis K. Proporsi Pasien Dermatitis Seboroik di RSUP H. Adam Malik Medan periode Tahun 2010-2012 [Skripsi]). Medan: Fakultas Kedokteran Universitas Sumatera Utara; 2014.

5. Terroe R. Profil Dermatitis seboroik di poliklinik kulit dan kelamin RSUP Prof. R. D. Kandou Manado periode Januari-Desember 2012 [Skripsi]. Manado: Fakultas Kedokteran Universitas Sam Ratulangi; 2014.

6. Goldenberg G. Optimizing treatment approaches in seborrheic dermatitis. Journal of Clinical Aesthetic Dermatology. Dermatology. 2013;6:44-9.

7. Thaha A. Hubungan kepadatan spesies malassezia dan keparahan klinis dermatitis seboroik di kepala. Jurnal Kedokteran \& Kesehatan. 2015;2:124-9.

8. Djuanda A, Hamzah M, Aisah S. Ilmu Penyakit Kulit \& Kelamin (6th ed). Jakarta: Balai Penerbit FKUI, 2010.

9. Berk T, Scheinfeld N. Seborrheic dermatitis. Pharmacy \& Theurapetics. 2010;35:348-55.

10.Mokos Z, Kralj M, Basta A, Jukic I. Seborrheic dermatitis an update. Dermatology and Venereology. 2012;20:98-104.

11.Dorland W. In: Elseria R, Mohede A, editors. Kamus kedokteran Dorland. (31st ed). Jakarta: EGC, 2010; p. 582.

12.Fritsch PO, Reider N. Other eczematous eruptions. In: Bolognia, Joziono, Rapini, editors. Dermatology. New York: Mosby Elsevier; 2008; p. 197- 
Malak, Kandou, Pandaleke: Profil dermatitis seboroik...

200.

13.Gayatri L, Barakbah J. Dermatitis seboroik pada HIV/AIDS. Kulit \& Kelamin. 2011;23:229-32.
14.Naldi L, Rebora A. Seborreic dermatitis. NEJM. 2009;360(4):387-96. 